\title{
Research on the development of tourism informatization in Harbin under the perspective of "tourism + Internet"

\author{
Qiang $\mathrm{Yu}^{1, \mathrm{a}}$, Lanlan $\mathrm{Liu}^{1, \mathrm{~b}}$ \\ ${ }^{1}$ Harbin University Harbin China \\ ayuqiang0708@163.com, bliulanlan_001@163.com
}

Keywords: Tourism informatization, Tourism + Internet, Research.

\begin{abstract}
Under the guidance of the "tourism + Internet" development strategy, we accelerated the development of tourism informatization. Through the use of information technology to change the traditional tourism production, distribution and consumption mechanism, with the concept of information development to optimize the operation of tourism economy, to achieve the rapid growth of tourism economy. At present, the application of information technology in the tourism industry of Harbin is constantly developing in depth, but it does not form the scale advantage and linkage effect, which is manifested in the information service function of the tourism management platform is not strong, the development and utilization of the large data and the tourism management information system are lagging behind. Aiming at the problems and deficiencies in the development of tourism informatization in Harbin, this paper puts forward corresponding countermeasures and plans.
\end{abstract}

\section{“旅游+互联网”视國下哈尔滨市旅游信息化发展建设的研究$$
\text { 于强1, a,刘岗岗 }{ }^{1, b}
$$$$
\text { 1哈尔滨学院, 哈尔滨, 中国 }
$$$$
\text { ayuqiang0708@163.com, bliulanlan_001@163.com }
$$

关键词: 旅游+互联网; 旅游信息化; 研究

中文摘要. 在 “旅游+互联网” 发展战略指引下加快了旅游信息化发展进程。通过对信息技术 的运用来改变传统的旅游生产、分配和消费机制, 以信息化的发展理念来优化旅游经济的运 作, 实现旅游经济的快速增长。目前, 哈尔滨市旅游产业信息化技术应用不断向纵深发展, 但没有形成规模优势和联动效应, 具体表现在旅游管理平台的信息化服务功能不强, 大数据 和旅游管理信息系统的开发利用和建设滞后等方面; 本文针对哈尔滨市旅游信息化发展中存 在的问题和不足提出了相应的对策和方案。

\section{1. 哈尔滨市旅游产业信息化发展现状}

在2016年5月的哈尔滨市十四届人大五次会议上审议通过的《哈尔滨市国民经济和社会发 展第十三个五年规划纲要》中明确提出落实 “互联网 + ” 行动计划, 发展分享经济, 制定实施 哈尔滨市 2020 “互联网+” 行动方案, 把握 “融合、创新、变革、引领” 的发展主线, 主动运 用互联网思维推动资源配置、技术创新、产业发展、商业模式创新和体制机制创新, 搭建 “互 联网+” 开放共享平台, 加强公共服务, 开展政务等公共数据开放利用, 鼓励创新平台向企业 特别是中小企业在线开放, 推动互联网与经济社会融合发展, 加快新型业态培育, 强化创业 
创新能力, 促进传统产业转型升级。这一战略的实施必将促进我市旅游产业信息化发展建设 步伐, 对提升旅游产业的竞争力, 目标实现我市智慧旅游的发展目标明确方向注入动力。

\section{1 旅行社企业信息化建设现状}

在哈尔滨旅游政务网上可查到于2012年公布的首批A级旅行社名录，其中有11家旅行社 企业上榜。其中多家旅行社企业均开通建设了各自企业的互联网门户网站, 如哈尔滨铁道国 际旅行社的官方网站上企业文化宣传内容丰富、旅游线路和产品推荐分类清晰详细、网站还 具有较强的营销反馈和线上互动功能; 黑龙江天马国际旅行社还在网站上设计了用户注册服 务, 能够通过后台数据库更详细全面收集和整理用户信息资源; 还有旅行社企业积极利用微 信自媒体等移动互联网平台创新企业宣传和推广的方式手段, 如哈尔滨蓝太阳商务旅行社的 微信公众平台不仅定期更新企业旅游推介项目, 而且还在微信公众平台上宣传最新行业动态 信息和旅游攻略，极大拉近了尤其是年轻客户群体的营销宣传和服务距离。

\section{2酒店企业信息化建设现状}

酒店企业的信息化建设主要体现在管理、服务、营销三个方面的应用。在互联网时代的 今天, 酒店企业的信息化建设水平以及互联网配套设施的完整性直接影响着人们旅行住宿的 消费体验。我们以三星级以上酒店为主要调查研究, 在黑龙江省旅游发展委员会政务网站上 发布的哈尔滨市星级酒店名录中, 五星级2家、四星级23家、三星级46家。从管理信息化层面, 所有酒店企业均引进或开发了适合各自企业评级要求的SOP (Standard Operating Procedures, 标准经营程序) 或PMS ( Property Management System酒店经营管理系统) 各类酒店管理信息 系统帮助酒店企业在实现客房管理、设施调度、客户结算等日常业务流程操作的信息化和规 范化; 从服务信息化建设层面, 各星级酒店企业在提供住宿餐饮服务以及配套休闲娱乐等服 务方面除了严格按照各自星级服务标准提供必要配套的硬件设施外, 我们重点考察酒店企业 在互联网接入方面的配套建设, 经过调查梳理, 哈尔滨五星级酒店的互联网接入服务配套设 施完善, WIFI覆盖无死角。四星级酒店企业在客房内大多提供比较完善的互联网有线连接服 务, 能够方便满足旅行者笔记本电脑的互联网接入服务。三星级酒店企业大多在酒店大堂或 公共休息区提供了无线互联网接入服务, WIFI覆盖区域信号强网速快; 在营销信息化建设层 面, 不同星级酒店企业的重视程度和建设方面存在较大差异, 哈尔滨香格里拉大饭店和哈尔 滨万达索菲特大酒店两家五星级酒店企业都开通建设了企业自己的门户网站, 基于各自的网 站平台独立宣传各自企业的文化和产品, 营销活动的宣传更新更加精准实时。

\section{3 旅游景区信息化建设现状}

旅游景区的信息化建设起步晚但发展建设快，信息化建设的技术含量更高更复杂，旅游 景区信息化涉及的各类应用技术研究包括GIS、Web GIS、VRGIS、GPS、RS、虚拟现实技术、 移动通信技术、计算机技术、数据库技术、网络技术、物联网、云计算等，这些信息技术的 广泛应用极大地提升了景区信息化的信息化服务能力和水平, 是旅游产业信息化建设中最具 科技含量的实践应用领域。自2010年提出 “智慧旅游” 概念后, 我国旅游产业的信息化建设 进程明显加快, 旅游景区在管理、服务和营销等方面的信息化建设程度和信息技术得到充分 的应用和推广，经过多年实践探索的经验证明了旅游产业与互联网技术融合发展的必要性和 可行性，2015年国家旅游局颁布制定了实施 “旅游+互联网” 行动计划的通知, 明确了 “旅游 +互联网” 发展模式的总体任务和目标, 为旅游与互联网融合发展指明了方向, 激发了活力, 为旅游产业的结构升级和发展创新提供了前所未有的发展机遇。目前, 我市星级旅游景区的 建设稍显落后, 景区的建设者和管理者普遍注重景点基础设施的建设而忽视信息化方面的建 设投入, 景区内WIFI等移动互联技术的普及应用还十分贵乏, 景区内的讲解和介绍仍然依靠 固定展板或导引牌为主, 电子导游的应用比例还很低。在旅游景区的电商营销组合策略上, 我市旅游景区的积极性依然不高, 重视程度不够。以阿里旅行为例, 做为刚刚评选为十大旅 
游避暑目的地的哈尔滨, 在阿里旅行平台上可供查询的本地游词条仅有 52 条, 而相比北京、 青岛等旅游城市差距明显。

\section{2. 哈尔滨市旅游产业信息化建设中存在的问题}

\section{1 旅行社企业互联网营销手段和意识淡薄}

旅行社企业是旅游产业结构中极其重要的组织环节，旅行社企业不仅是旅游消费市场的 引导者, 同时也是旅游市场服务输出的供给者, 是促进旅游市场繁荣有序发展的调和剂。近 年来，随着 “冰城夏都” 这一独具特色的旅游城市名片使哈尔滨在全国旅游城市中的知名度 和美誉度逐年提升, 哈尔滨市的旅游消费市场规模发展很快, 这给哈尔滨当地的旅行社企业 带来了巨大商机, 依据哈尔滨旅游政务网站截至2016年1月份统计公布的结果显示, 哈尔滨地 区从事不同业务范围的旅行社企业333家，然而，经过我们采样调查发现，大概三分之二的旅 行社企业依然采用传统的业务营销模式，业务咨询和客户服务仍然依靠电话传真等原始的沟 通方式，有的企业甚至没有足够宽敞的办公场所，仅仅具备必要的计算机办公设备和简单的 OA软件，这种业务经营管理模式显然太过粗放，突显旅行社企业对互联网时代背景下的信息 化营销方式和手段缺乏了解和认知。突显了哈尔滨旅行社企业整体信息化服务能力的水平和 质量十分低级, 究其原因大多是旅行社企业只追求经济利益而忽视营销服务创新的主观因素 造成的。

\section{2 景区信息化设施建设滞后}

近些年来，哈尔滨的景区（点）建设规划发展迅速，一批批新建景区（点）陆续营业, 极大地提升了哈尔滨市旅游市场吸引力。然而, 景区 (点) 在规划设计阶段一味追求硬件和 基础设施的建设投资，对于信息化服务功能的规划设计不足，导致很多景区（点）任然没有 摆脱 “靠山吃山，靠海吃海” 传统思维。景区（点）的规划设计者缺乏对信息化技术应用和 实践的认知和意识, 没有认识到信息化服务功能具有提升旅行者旅游体验以及提高景区 (点) 核心竞争力的增值功能。

\section{3 酒店企业信息化配套设施建设不完善}

酒店企业的信息化建设起步早，行业发展比较均衡规范。在不同等级的酒店等级评定标 准中对企业信息化建设的设施和投入都有明确的要求和规定。然而, 多年来, 随着信息技术 的不断发展，对于早期评定标准中的相关技术指标以及稍显落后难以跟上互联网时代发展的 最新潮流和趋势, 比如网速的指标, WIFI的使用便利性和覆盖范围等都缺乏明确具体的约束 指标, 一些酒店企业的信息化配套设备陈旧老化, 需要重新铺设必要的管网设施才能确保信 息服务的质量和满意度，但是由于行业等级评定没有及时调整评定指标标准，因此酒店企业 的改造意愿和主观意识不强, 导致一些酒店企业甚至是星级酒店企业的信息化服务能力和水 平与某些快捷酒店比在网速和覆盖范围上存在巨大差异。

\section{3. 哈尔滨市旅游产业信息化建设的对策研究}

\section{1 规划建设旅游大数据中心提升旅游产业信息化服务质量}

旅游大数据中心的建设离不开地方政府主导下的旅游咨询网站、旅游政务网站、微信、 微博等信息系统所处理的集成数据, 做为省会城市同时也是黑龙江省的主要旅游集散地, 哈 尔滨旅游管理部门在大数据中心建设中具有得天独厚的数据资源优势, 这就需要哈尔滨旅游 管理部门加强数据库系统的建设投入借助云计算和云存储等最新前沿技术构建哈尔滨的旅游 大数据服务平台, 基于该平台要建立与旅行社企业、酒店企业、景区、民航交通运输部门、 气象服务部门、海关统计部门等的数据共享机制, 基于大数据平台综合运用信息采集、数据 挖掘的相关技术提升哈尔滨市旅游产业信息化综合服务的能力和水平。 


\section{2 加快完善旅游产业互联网基础设施的建设工作}

哈尔滨做为我省 “旅游+互联网” 试点城市, 在互联网基础设施建设规划和投入上还需要 进一步加快落实节奏。以2015年四季度公布的统计数据对比分析, 我市星级酒店企业的平均 入住率和平均房价普遍低于国内平均水平，当前我市酒店企业的入住环境尤其是网络配套设 计的环境建设严重滞后, 建设标准参差不齐导致酒店行业的整体竞争实力与旅游发达城市相 比还有较大差距, 如果我市的酒店企业能够尽快完善互联网基础设施的配套建设, 极力提升 信息化服务水平，酒店企业必将迎来量价齐升的新局面。

另外，当前我市旅游景区（点）建设发展很快，如果不能把好信息服务质量关，极容易 造成旅游市场供给的鱼龙混杂，互联网时代背景下，信息化的建设投入已经不再是锦上添花 的附带工程, 而应当是必备工程, 这就要求旅游监督规划部门要有信息化建设的前瞻性和必 要的干预手段，对于旅游景区（点）的信息化配套设施不完善，达不到 “旅游+互联网” 行动 计划建设要求的一律杜绝审批, 对已建景区（点）的信息化服务的基础设施建设和投入以及 信息化服务能力和水平要有严格的监督评价，不达标的企业要坚决限时整改。

\section{3完善旅游营销组合策略}

互联网时代为我们带来的电子商务颠覆了很多传统企业的商业模式，而旅游电商却是融 合发展的共赢模式。基于互联网技术应运而生的电子商务具有虚拟营销的渠道优势，而旅游 企业掌握着旅游市场的资源优势，因此，当二者携手合作开创旅游营销创新模式的时候自然 就会产生 $1+1>2$ 的化学反应。在互联网技术的支持下, 旅游电商的创新型营销模式具有成本低、 交互性强的优点, 而且营销服务对象精准, 便于针对不同营销对象开发差异化个性化的旅游 消费产品。纵观国内旅游发达城市, 旅游企业大多向OTA（Online Travel Agent, 在线旅行社） 或OTS（Online Travel Supplier,在线资源型旅行社）的方向发展，基于互联网甚至是移动互联 网技术发展而来的OTA或OTS无论从规模上还是合作的深度和广度上都有较成熟的实践探索。 近年来涌现出的旅游电商企业如携程旅游、同程旅游、驴妈妈、途牛网等纷纷向传统旅游企 业伸出合作之手，传统旅游企业要及时调整发展思路与方向，与OTA或OTS加强合作，将电 商平台的渠道优势与旅游企业的资源优势强势联合，提升旅游消费者的消费体验，满足不同 旅游消费群体的差异化服务。

\section{致谢}

本文为哈尔滨市市社科联调研项目《“互联网+旅游”背景下哈尔滨旅游信息发展研究》 研究成果之一。

\section{References}

[1] Jennifer Xiaoqiu Ma; Dimitrios Buhalis; Haiyan Song, ICTs and Internet adoption in China's tourism industry, International Journal of Information Management, vol.116, pp. 451-467, 2003.

[2] Thomas C. Chuang; John S. Liu; Louis Y. Y. Lu; Fang-Mei Tseng; Yachi Lee; Chih-Ting Chang; The main paths of eTourism: trends of managing tourism through Internet, Asia Pacific Journal of Tourism Research, vol.108, pp. 213-231, 2017.

[3] Ratidanai Hoonsawat, Information Searching: The Case of Tourism Promoted Through the Internet, Global Economy Journal, vol.115, pp. 33-37, 2016. 